\title{
Cholesterol of lipid rafts is a key determinant for entry and post-entry control of porcine rotavirus infection
}

\author{
Xiujing Dou ${ }^{1 \dagger}$, Yang $\mathrm{Li}^{1 \dagger}$, Junlan Han ${ }^{1}$, Dante S. Zarlenga ${ }^{2}$, Weijuan Zhu' ${ }^{1}$ Xiaofeng Ren ${ }^{1}$, Na Dong ${ }^{1}$, \\ Xunliang $\mathrm{Li}^{1^{*}}$ and Guangxing $\mathrm{Li}^{1^{*}}$
}

\begin{abstract}
Background: Lipid rafts are major structural components in plasma membranes that play critical roles in many biological processes including virus infection. However, few reports have described the relationship between lipid rafts and porcine rotavirus (PRV) infection. In this study, we investigated whether or not the locally high concentrations (3-5 fold) of cholesterol present in lipid rafts are required for PRV infection, and further examined which stages of the infection process are most affected.

Results: When cellular cholesterol was depleted by methyl- $\beta$-cyclodextrin $(M \beta C D)$, PRV infectivity significantly declined in a dose-dependent manner. This inhibition was partially reversed upon reintroduction of cholesterol into the system. This was corroborated by the co-localization of PRV with a recombinant, GPI-anchored green fluorescent protein, which functioned as a marker for membranous regions high in cholesterol and indicative of lipid rafts. Changes in virus titer and western blot analyses indicated that depletion of cellular cholesterol with M $\beta C D$ had no apparent effect on PRV adsorption; however, depletion of cholesterol significantly restricted entry and post-entry of PRV into the cell. Both points of inhibition were restored to near normal levels by the addition of exogenous cholesterol.

Conclusions: We conclude from these studies that membrane-based cholesterol and in particular that localized to lipid rafts, is an indispensable biomolecule for PRV infection, and that cholesterol-based control of the infection process takes place during entry and immediately post-entry into the cell.
\end{abstract}

Keywords: Porcine rotavirus (PRV), Lipid rafts, Cholesterol, Methyl- $\beta$-cyclodextrin (M $\beta C D)$, Infection, Entry

\section{Background}

Porcine rotavirus (PRV) is the most important cause of severe diarrhea in newborn piglets, and results in significant economic loss to pig industry. To date, efficient drugs for preventing PRV infection have not been identified. PRV, which belongs to the genus Rotavirus in the family Reoviridae, is a non-enveloped virus formed by three concentric layers of proteins [1]. The outermost layer consists of spike-like structures comprised of an unglycosylated VP4 protein [2] and a glycoprotein VP7, which forms the smooth surface of the virus. VP7 is a calcium-binding

\footnotetext{
*Correspondence: 14746768@qq.com; ligx@neau.edu.cn

${ }^{\dagger}$ Equal contributors

${ }^{1}$ Northeast Agricultural University, No. 59 Mucai Street, Xiangfang District,

Harbin 150030, China

Full list of author information is available at the end of the article
}

protein that interacts with cell receptors after the initial attachment of the virus to the cell surface [3].

It remains unclear as to how non-enveloped viruses which lack an outer lipid membrane infect host cells. It is generally believed that membrane fusion is not involved in virus entry and that release of these viruses is mainly performed by cell lysis [4]. It has been proposed that non-enveloped viruses penetrate the membrane barrier, either by the formation of a pore at the cell surface, or via the endocytic pathway using clathrin-coated vesicles or caveolae [4]. Alternatively, studies with simian virus 40 (SV40) [5] and poliovirus [6] have suggested that non-enveloped viruses are transported to specific domains within the plasma membrane using a vesicular transport mechanism, followed by replication in large inclusions in 
the cell cytoplasm or viroplasm [7]. Other biochemical and structural studies have shown that the overall mechanism is similar to enveloped viruses, and that viral capsid proteins may function in a manner analogous to the membrane viral proteins [4].

In recent years, research has exposed a crucial role for lipid rafts in a variety of virus life cycles [6-8]. Lipid rafts are traditionally described as microdomains within plasma membranes that are high in cholesterol, sphingolipids, glycosyl-phosphatidylinositol (GPI)-anchored proteins, and a specific set of associated proteins often cell receptors. They are thought to provide organization to and stabilize the structure of cell membranes because the high concentration of sphingolipids and protein receptors are densely packed together with cholesterol [9]. Although they are more ordered and closely packed, they still have the ability to float freely within the membrane bilayer. The most commonly used drugs to control the formation and function of lipid drafts are nystatin and filipin which sequester cholesterol, $\mathrm{M} \beta \mathrm{CD}$ which is used to deplete membrane-bound cholesterol, and lovastatin which inhibits cholesterol biosynthesis [8].

Recent reports have demonstrated the involvement of lipids in a variety of cellular functions such as apical cell-sorting of proteins, signal transduction, caveolae mediated endocytosis, and viral release, assembly and budding in the cell membrane. These have been well documented in human immunodeficiency virus (HIV) [9], measles virus [10], influenza virus [11-13] and rotavirus $[7,14]$. Lipids have also been deemed important in intracellular trafficking of viral proteins [15-18] (e.g. echovirus types 1 and 11, Ebola [19]), and provide platforms for cell entry (e.g. SV40 [20], HIV [21-24], echovirus type 1 [25] and rhesus rotavirus (RRV) [14]). Although it has been reported that RRV depends upon lipid rafts for cell entry [14], the specific role of cholesterol in these processes of PRV remains elusive.

Herein, we explored the importance of cellular cholesterol during PRV infection of MA104 cells by demonstrating that viral protein and genomic RNA levels were reduced significantly following $\mathrm{M} \beta C D$ treatment to deplete cellular cholesterol. We further showed that viral protein and genomic RNA levels were restored by subsequently treating the cells with exogenous cholesterol. Data showing the colocalization of VP7 with recombinant, fluorescently-labeled GPI-anchored protein linked the virus predominantly to lipid rafts. In as much as cholesterol was indispensable for both PRV entry and the post-entry process, lipid rafts could be a target for development of anti-PRV strategies.

\section{Methods}

Cells, viruses, antisera and reagents

MA104 and BHK-21 cells (obtained from China Center For Type Culture Collection) were cultured in Dulbecco's
Modified Eagle Medium (DMEM) (Gibco) supplemented with $10 \%$ fetal calf serum (FCS) at $37{ }^{\circ} \mathrm{C}$ under $5 \% \mathrm{CO}_{2}$. PRV (strain DN30209, isolated in a pig farm, in Heilongjiang province of China) [26] and vesicular stomatitis virus (VSV, strain Indiana, obtained from prof. Joerg Glende, University of Veterinary Medicine Hannover, Germany) were propagated on the MA104 cells and BHK-21 cells, respectively, as previously described $[26,27]$. In as much as previous reports showed that VSV infection on BHK-21 is not affected by depletion of cholesterol [27], we used VSV as a negative control for our studies about relationship between lipid rafts and virus infection.

Rabbit polyclonal antibodies to VP4 and VP7 were generated in our laboratory using previously described methods [26, 28]. Anti-VSV G-protein polyclonal antibody was purchased from Abcam. An anti- $\beta$-actin monoclonal antibody was purchased from Beyotime. The secondary antibodies were purchased from BD Biosciences. Both $M \beta C D$ and cholesterol were purchased from Sigma and reconstituted in DMEM and alcohol, respectively.

\section{Virus titration}

Approximately $1 \times 10^{4}$ MA104 or BHK-21 cells were seeded onto 96-wells plates then incubated with purified PRV or VSV (100 $\mu \mathrm{L}$ virus/well) that was serially-diluted 10 -fold prior to infection. Forty-eight hours after infection, the $50 \%$ tissue culture infectious dose $\left(\mathrm{TCID}_{50}\right)$ of each well was determined according to the method of Reed and Muench by observing cytopathic effects (CPE). All experiments were conducted 5 times.

\section{Cytotoxicity assay}

Toxic effects of $\mathrm{M} \beta \mathrm{CD}$ and cholesterol on cells were determined using the Mosmann based assay (MTT) [29]. Cells were plated onto 96-well plates and upon reaching $80 \%$ confluency, they were incubated with different concentrations of $\mathrm{M} \beta C D(0,2,4,6,8,10,15 \mathrm{mM})$ or cholesterol (0, 50, 100, 150, $200 \mu \mathrm{M})$ for $48 \mathrm{~h}$. Mock-treated cells served as controls.

\section{Depletion and replenishment of cholesterol from cells}

For cholesterol depletion, cell monolayers were grown to $80 \%$ confluency, washed three times with cold phosphatebuffered saline (PBS), and then treated with various concentrations of $M \beta C D$ ranging from 2 to $15 \mathrm{mM}$ in serum-free DMEM for $30 \mathrm{~min}$ at $37^{\circ} \mathrm{C}$. Control cells were similarly treated but received no $\mathrm{M} \beta \mathrm{CD}$. All cells were subsequently washed with cold PBS. For cholesterol replenishment, washed cells were treated for $1 \mathrm{~h}$ at $37^{\circ} \mathrm{C}$ with DMEMsoluble exogenous cholesterol at final concentrations ranging from 50 to $200 \mu \mathrm{M}$. Again the cells were washed extensively with PBS then subjected to virus $\left(100\right.$ TCID $\left._{50}\right)$ infection. 
Indirect immunofluorescence assay (IFA)

At $24 \mathrm{~h}$ post-infection, all cells were washed and fixed with cold $1 \%$ paraformaldehyde for $30 \mathrm{~min}$, and then balanced out by glycine $5 \mathrm{~min}$. The cells were washed and permeabilized with $1 \%$ Triton X-100 for $10 \mathrm{~min}$, and then incubated with $200 \mu \mathrm{L}$ polyclonal antibody against the PRV VP7 protein or VSV-G protein at $37^{\circ} \mathrm{C}$ for $45 \mathrm{~min}$. After washing, the cells were incubated with an optimum dilution of fluorescein (FITC)-conjugated goat anti-rabbit IgG $(\mathrm{H}+\mathrm{L})$ (OriGene, Beijing) for $30 \mathrm{~min}$ at $37{ }^{\circ} \mathrm{C}$ then washed again in the dark, and examined under a fluorescence microscope (Zeiss Axiovert 200).

\section{Co-localization of PRV VP7 and GPI-anchored protein}

MA104 cells were seeded onto 24-well tissue culture plates $\left(2 \times 10^{5}\right.$ per well $)$ and transfected using lipofectamine 2000 (Invitrogen, USA) with the pEGFP-GPI, a DNA plasmid encoding GPI-tethered to the enhanced green fluorescent protein (provided by Kai Simons, Max-Planck-Institute of Molecular Cell Biology and Genetics, Germany). At $6 \mathrm{~h}$ post-transfection, cells were infected with PRV (100 $\mathrm{TCID}_{50}$ ) for $24 \mathrm{~h}$ at $37^{\circ} \mathrm{C}$. Polyclonal antibody to PRV VP7 protein was used for virus detection by IFA using a fluorescence microscope.

\section{Real-time PCR}

Real time-PCR was used to evaluate and quantify the level of viral infection following treatment. Briefly, total genomic RNA was extracted from viruses using RNA extract reagent (Fastgene, China) and cDNA was synthesized using M-MLV reverse transcriptase (Takara Bio Inc., Shiga, Japan). The cDNA was PCR amplified and the products were quantified using SYBR green as fluorescence dye (Takara Bio Inc., Shiga, Japan). The data were analyzed with ABI PRISM 7500 SDS software. Gene quantification was performed using the $2^{-\Delta \Delta C T}$ method. The primer sequences are shown in Table 1.

\section{Western blot}

The cells were harvested and lysed with cold cell lysis buffer containing 1\% Triton X-100 and 1\% protease inhibitor (Beyotime Institute of Biotechnology, USA). Total lysate was separated on a $12 \%$ SDS-PAGE gel then transferred to nitrocellulose membranes. The membranes were blocked

Table 1 The primer sequences used for real-time PCR

\begin{tabular}{lll}
\hline Gene & \multicolumn{2}{l}{ Primer sequence (5' to 3') $^{\prime}$} \\
\hline VP7 & Forward & TGTCCTCTAAATACGCAGACTC \\
\multirow{3}{*}{-actin } & Reverse & CTACCTGAATACAGCGACAT \\
& Forward & GGCTCAGAGCAAGAGAGGTATCC \\
VSV-G & Reverse & GGTCTCAAACATGATCTGAGTCATCT \\
& Forward & TTCAAGCAGACGGTTGG \\
& Reverse & TGCTTCGGCATCCGTCA \\
\hline
\end{tabular}

with $5 \%$ non-fat dry milk in Tris-buffered saline $(10 \mathrm{mM}$ Tris- $\mathrm{Cl}$ at $\mathrm{pH} 7.5$ and $150 \mathrm{mM} \mathrm{NaCl}$ ) containing $0.05 \%$ Tween 20 (TBST) at $37^{\circ} \mathrm{C}$ for $1 \mathrm{~h}$, and then incubated with primary antibody at room temperature for $4 \mathrm{~h}$. Detection was performed using horseradish peroxidase (HRP)-linked secondary antibody at room temperature for $1 \mathrm{~h}$. Blots were developed using enhanced chemiluminescence detection system (Applygen, China).

\section{Stage specificity of cholesterol effects on PRV infection}

To investigate the effects of cholesterol depletion on PRV infectivity in MA104 cells, the cell monolayers were incubated with $8 \mathrm{mM}$ or $15 \mathrm{mM} \mathrm{M} \beta C D$ for $30 \mathrm{~min}$ at $37{ }^{\circ} \mathrm{C}$, then washed. Virus $\left(100 \mathrm{TCID}_{50}\right)$ was inoculated onto the cells at $4{ }^{\circ} \mathrm{C}$ where only adsorption can occur. After $2 \mathrm{~h}$, the unbound virus was removed by washing and the medium replaced with DMEM. The cells were cultured until control cells exhibited complete CPE. For cholesterol replenishment, cells were pretreated with $15 \mathrm{mM} \mathrm{M} \beta \mathrm{CD}$ at $37^{\circ} \mathrm{C}$ for $30 \mathrm{~min}$, washed, then incubated with $200 \mu \mathrm{M}$ cholesterol for $1 \mathrm{~h}$ at $37{ }^{\circ} \mathrm{C}$. The cells were then incubated with PRV at $100 \mathrm{TCID}_{50}$ for $2 \mathrm{~h}$ at $4{ }^{\circ} \mathrm{C}$.

For studies on cell entry, the cells were mock treated or pretreated with $8 \mathrm{mM} \mathrm{M} \beta C D$ at $37^{\circ} \mathrm{C}$ for $30 \mathrm{~min}$ then infected with $\operatorname{PRV}\left(100 \mathrm{TCID}_{50}\right)$ for $1 \mathrm{~h}$ at $37{ }^{\circ} \mathrm{C}$, after which remaining virus was removed by washing. The cells were kept in serum-free DMEM at $37{ }^{\circ} \mathrm{C}$ until mock treated, virus-infected cells showed complete CPE. For cholesterol replenishment, cells were pretreated with $15 \mathrm{mM} \mathrm{M} \beta \mathrm{CD}$ at $37{ }^{\circ} \mathrm{C}$ for $30 \mathrm{~min}$, washed and then incubated with exogenous cholesterol $(200 \mu \mathrm{M})$ for $1 \mathrm{~h}$ at $37^{\circ} \mathrm{C}$.

For the post-entry study, cells were infected with PRV $\left(100 \mathrm{TCID}_{50}\right)$ for $1 \mathrm{~h}$ at $37{ }^{\circ} \mathrm{C}$, and the remaining virus was removed by washing. The cells were subsequently mock treated or pretreated with $8 \mathrm{mM} \mathrm{M \beta CD}$ at $37{ }^{\circ} \mathrm{C}$ for $30 \mathrm{~min}$, washed in cold PBS and then incubated in DMEM at $37{ }^{\circ} \mathrm{C}$ until the mock treated, virus-infected cells showed complete CPE. For cholesterol replenishment, the cells were treated as described for the cell entry studies. Western blots and virus titers were performed to assess the effects of pre- and post-treatment on virus infection.

\section{Results}

\section{Effects of cholesterol depletion on PRV infection}

To determine whether the cholesterol component of lipid rafts plays a role in PRV infection, the cholesterol level in cellular membranes of MA104 cells for PRV and BHK-21 cells for VSV, respectively, were depleted by treatment with $M \beta C D$ before infecting with PRV or VSV. After $24 \mathrm{~h}, \mathrm{VP7}$ polyclonal antibody for PRV binding exhibited a dose-dependent decrease in MA104 cells pretreated with increasing concentrations of $\mathrm{M} B C D$ (Fig. 1a). At a concentration of $15 \mathrm{mM}$, the infection rate 

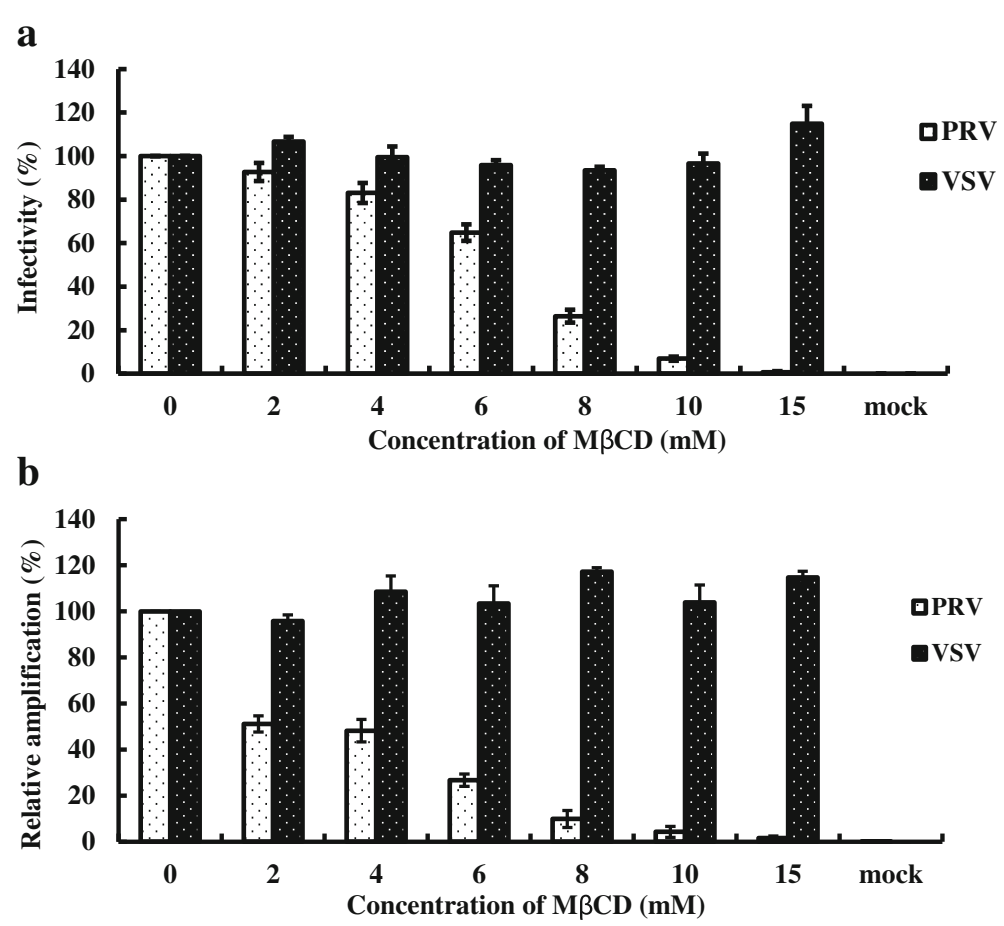

C

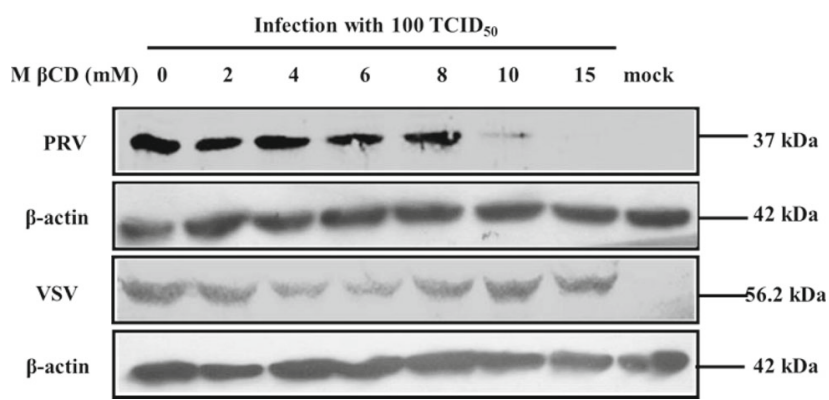

Fig. 1 PRV infection inhibited by cholesterol depletion with MBCD. MA104 cell and BHK-21 cell monolayers were treated with increasing concentrations of M $\beta C D$ before virus infection. Cells were subsequently, infected with PRV or VSV (100 TCID $\left.{ }_{50}\right)$ respectively, except "mock" as control without virus infection and MBCD treatment. a IFA data demonstrating infectivity of PRV and VSV using anti-VP7 of PRV antibodies and anti-G protein of VSV antibodies respectively. The $100 \%$ infectivity values of PRV and VSV represent average fluorescein-stained cells numbers of 100 and 240 , respectively. b Real-time PCR data for PRV and VSV targeting the VP7 gene and G-protein. c Western blot analysis using antibodies to VP7 for PRV, G-protein for VSV and $\beta$-actin served as a protein loading control. Error bars indicate the standard deviations of three independent experiments

of PRV decreased by $99 \%$. In contrast, the infection rate of cholesterol-depleted BHK-21 cells infected with the control VSV was not affected. Real-time PCR results to quantify the PRV VP7 and VSV G gene, the viral load showed a similar response in M $B C D$-treated cells (Fig. 1b). Western blot (Fig. 1c) also demonstrated that depletion of cholesterol reduced the level of PRV infection in a dose-dependent manner where VP7 protein expression was nearly absent from MA104 cells at $15 \mathrm{mM} \mathrm{M} \beta C D$. In contrast, no significant inhibitory effects were observed in $\mathrm{M} \beta C D$ treated BHK-21 cells infected with VSV as monitored by VSV G protein levels (Fig. 1c).

\section{Effects of cholesterol replenishment on PRV infection in} cholesterol-deficient cells

The effects of PRV-infection on MA104 cells depleted of cholesterol with $\mathrm{M} \beta C D(15 \mathrm{mM})$ then replenished with exogenous cholesterol prior to PRV infection, are shown in Fig. 2. Virus levels were examined directly by IFA assay (Fig. 2a) and indirectly by RT-PCR (Fig. 2b). PRV infectivity as examined by IFA, increased in a dose-dependent manner and was restored to $70 \%$ of pretreatment levels (no M $3 C D$ ) (Fig. 2a) with a concentration of $200 \mu \mathrm{M}$ cholesterol. From the RT-PCR, we observed a similar, dose-dependent increase in the level of VP7 gene of PRV as the amount of exogenous cholesterol was increased 


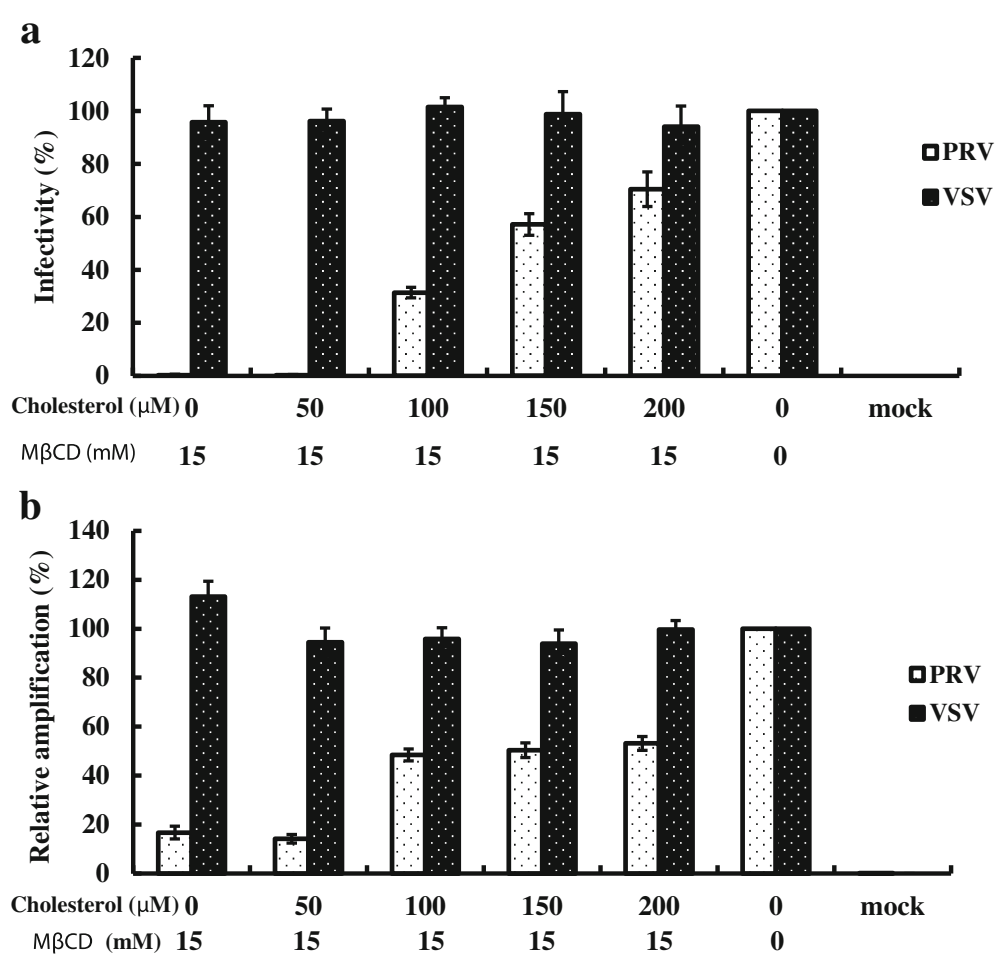

Fig. 2 The restoration of PRV-infectivity by exogenous cholesterol. MA104 cell and BHK-21 cell monolayers were treated with 15 mM MBCD before supplemented with exogenous cholesterol. Subsequently, cells were infected with PRV or VSV $\left(100\right.$ TCID $\left._{50}\right)$ respectively, except mock as control without virus infection and $\mathrm{M} \beta \mathrm{CD}$ / exogenous cholesterol treatment. a IFA data demonstrating infectivity of PRV and VSV using anti-VP7 antibodies and anti-VSV G protein antibodies respectively. The 100\% infectivity values of PRV and VSV represent average fluorescein-stained cells numbers of 160 or 230, respectively; b Real-time PCR data for PRV and VSV targeting the VP7 and G protein gene. Error bars indicate the standard deviations of three independent experiments

(Fig. 2b), the VP7 gene expression reached $55 \%$ pretreatment levels (no $M \beta C D$ ).

\section{Co-localization of PRV VP7 protein and GPI-anchored protein}

GPI-proteins have a predilection for lipid rafts. MA104 cells transfected first with GPI-pEGFP then with PRV $\left(100 \mathrm{TCID}_{50}\right)$ showed a co-localization of both the recomninant GPI-protein (green) (Fig. 3a) and the PRV
VP7 protein (red) (Fig. 3b) in dense regions of the cell membrane. These regions appeared yellow in merged figures (Fig. 3c). Data suggest that the PRV VP7 protein was localized in the lipid rafts of MA104 cells.

\section{Cholesterol is not required for PRV adsorption}

To determine if cholesterol is important in PRV adsorption, cholesterol-depleted cells were incubated with PRV for $24 \mathrm{~h}$ at $4{ }^{\circ} \mathrm{C}$ to prevent viral replication, and then assayed

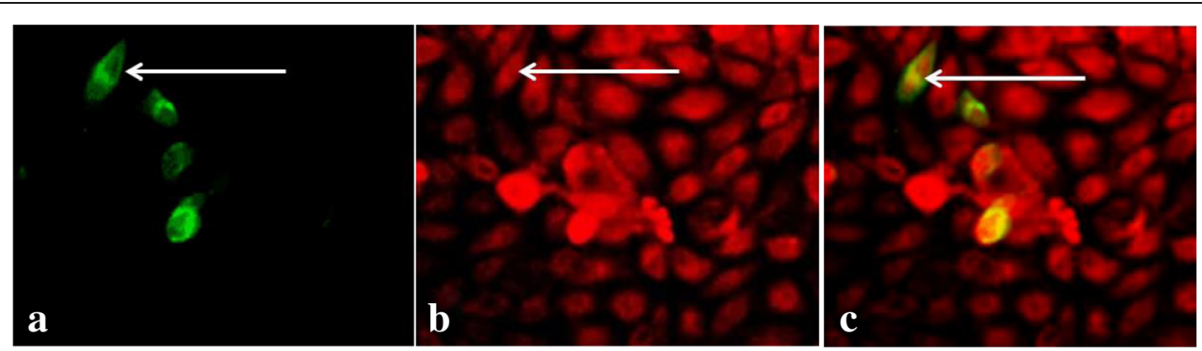

Fig. 3 Co-localization of PRV VP7 protein and plasmid-derived, recombinant GPI-anchored protein. MA104 cells were treated for IFA as follows: a cells transfected with a plasmid expressing GPI-anchored green fluorescence labeling; b PRV infected cells incubated with anti-VP7 protein antibodies and counterstained with FITC second antibody; c co-localization of GPI-anchored protein and PRV VP7 protein on the cell membrane (Fig. 3a and $\mathrm{b}$ merged). Yellow color depicts overlapping binding 
for viral load by $\mathrm{TCID}_{50}$ and western blot. As shown in Fig. 4a and b, relative to mock-infected groups, no remarkable inhibitory effects were observed by $\mathrm{TCID}_{50}$ or western blot in the PRV-infected groups. The results mirrored those obtained with VSV (Fig. 4a and c) which is not affected by cholesterol levels. Data suggest that adsorption onto the cell membrane was not affected in cholesteroldepleted cells.

\section{Cholesterol depletion inhibits PRV entry in a reversible} manner

To study the effects of cholesterol on PRV entry, cholesterol-depleted MA104 cells were incubated with PRV at $37^{\circ} \mathrm{C}$ rather than $4{ }^{\circ} \mathrm{C}$ then viral loads examined 24. h post-infection. Results show that PRV virus titers (Fig. 5a) and viral protein levels (Fig. 5b) were decreased. At a concentration of $8 \mathrm{mM} \mathrm{M} \beta C D$, we observed an approximate reduction in the virus titer of $50 \%$, relative to controls. Expression levels of PRV viral protein were also significantly reduced; however, VSV and $\beta$-actin were not changed (Fig. 5c).

The results on virus entry were reversible (Fig. 6). Cholesterol-depleted MA104 cells treated with $200 \mu \mathrm{M}$ exogenous cholesterol for $1 \mathrm{~h}$ showed complete restoration of PRV virus titers relative to mock treated cells (Fig. 6a). The viral protein levels were increased significantly (Fig. 6b). Levels of VSV were not affected (Fig. 6a and c). Results suggest that stages following adsorption and most likely virus entry have a strict requirement for cholesterol.

\section{Cholesterol depletion of MA104 cells inhibited PRV post-entry stage}

To analyze post-entry stages, MA104 cells were first infected with PRV then treated with $M \beta C D$. As shown

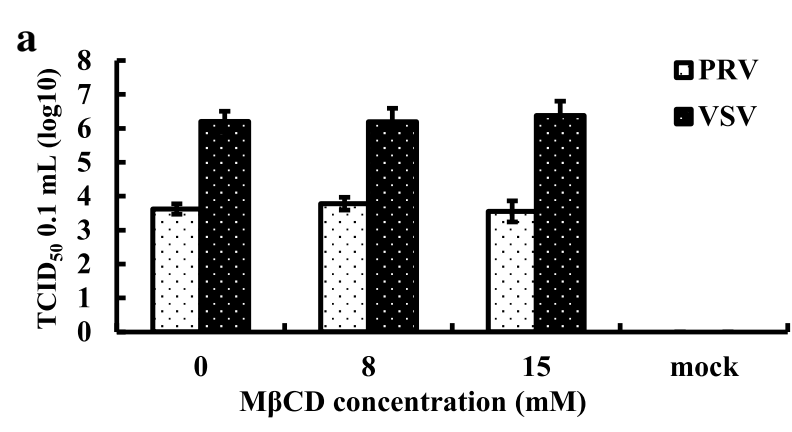

b PRV infection with 100 TCID $_{50}$

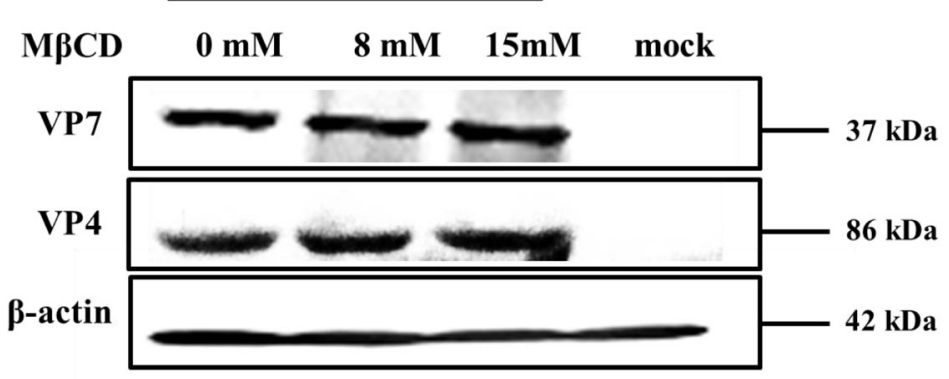

c VSV infection with 100 TCID $_{50}$

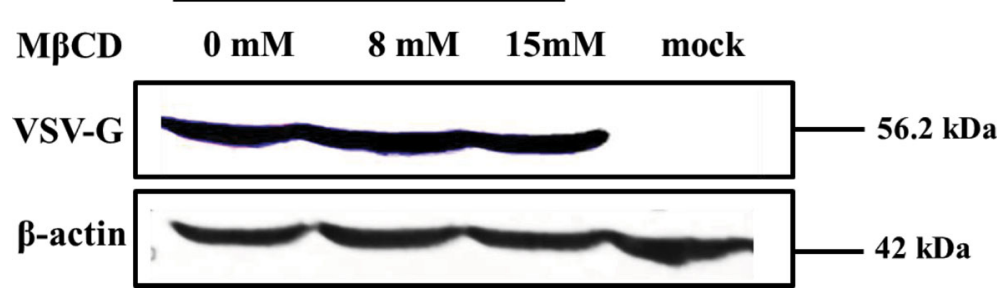

Fig. 4 Cellular cholesterol and PRV adsorption. MA104 cells (PRV) and BHK-21 cells (VSV) were either mock treated or treated with 8 mM or $15 \mathrm{mM} \mathrm{M \beta CD} \mathrm{for} 30 \mathrm{~min}$, then infected with PRV or VSV $\left(100 \mathrm{TCID}_{50}\right)$ at $4{ }^{\circ} \mathrm{C}$ for $2 \mathrm{~h}$. Antibodies to the PRV VP7 or VP4 proteins and to the VSV G protein were used to screen western blots of cell homogenates and virus titers. a Virus titers of PRV and VSV after treatment. $\mathbf{b}$ Western blot of PRV VP7 and VP4 proteins and $\beta$-actin. c Western blot of VSV G protein and $\beta$-actin. Western blots depict representative experiments. Error bars (Fig. 4a) indicate the standard deviations of three independent experiments 
a

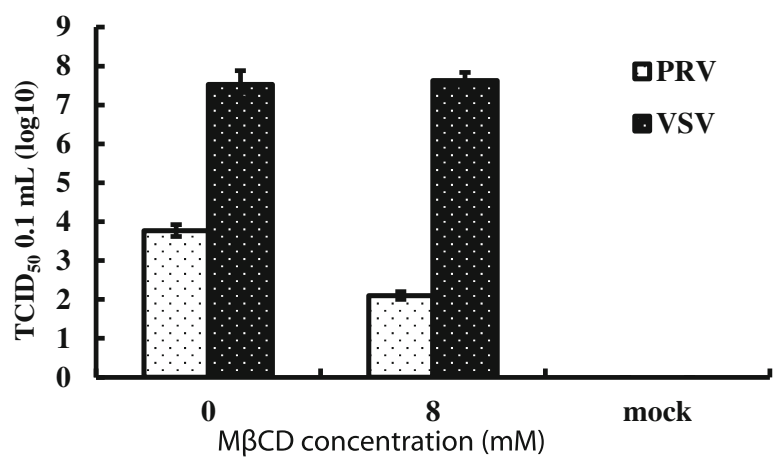

b PRV infection with 100 TCID $_{50}$

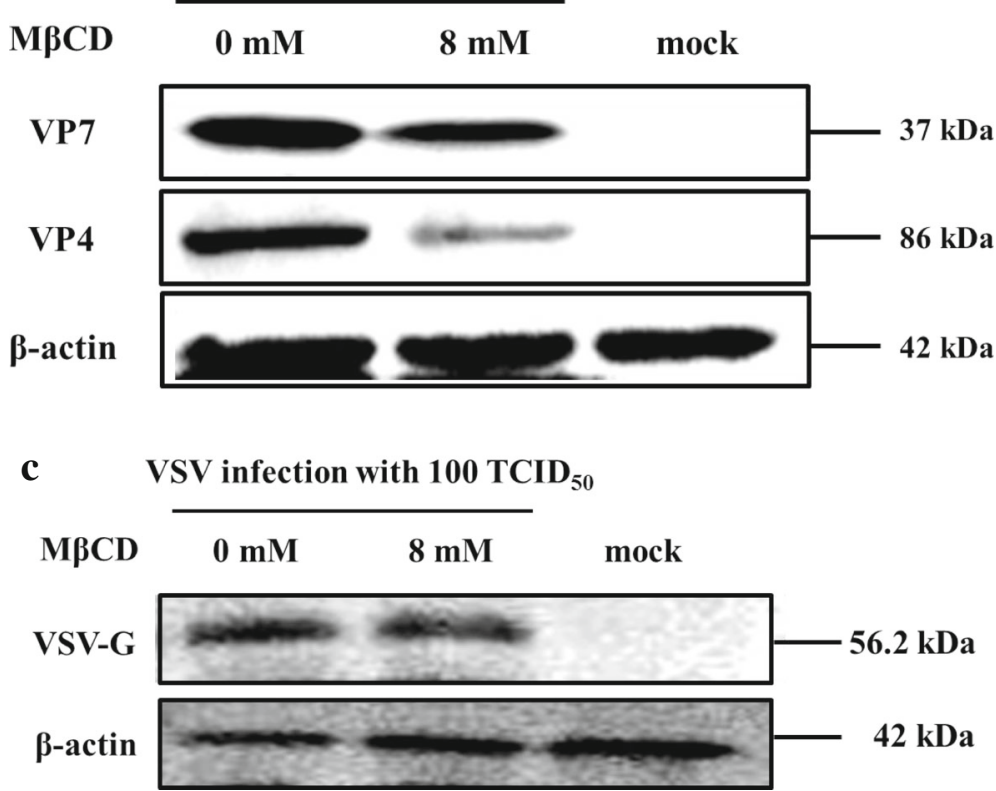

Fig. 5 Cholesterol and control of PRV entry. MA104 cells (PRV) and BHK-21 cells (VSV) were either mock treated or treated with 8 mM MBCD for 30 min then infected with PRV or VSV $\left(100 T \mathrm{TCID}_{50}\right)$ for $1 \mathrm{~h}$ at $37^{\circ} \mathrm{C}$. Antibodies to the PRV VP7 or VP4 proteins and to the VSV G protein were used to screen western blots of cell homogenates and virus titers. a Virus titers of PRV and VSV after treatment. $\mathbf{b}$ Western blot of PRV VP7 and VP4 proteins and $\beta$-actin. $\mathbf{c}$ Western blot of VSV G protein and $\beta$-actin. Western blots depict representative experiments. Error bars (Fig. 5a) indicate the standard deviations of three independent experiments

in Fig. 7a, b, and c, the PRV virus titers and viral protein levels decreased relative to VSV controls, whereas replenishing exogenous cholesterol restored virus titers to pretreatment levels relative to VSV controls (Fig. 8a). The viral proteins were also increased significantly (Fig. 8b) relative to VSV controls (Fig. 8c) demonstrating that post-entry stages were also controlled by the level of cellular cholesterol.

\section{Discussion}

Lipid rafts are densely packed, floating asemblages of cholesterol, sphingolipid and mostly receptor proteins that are present within cell membranes and that function in membrane trafficking and signaling [30]. Among other things, lipid rafts play critical roles in viral entry, replication, assembly and budding, as well as in protein transport [31]. Cholesterol is a key component of lipid rafts that compartmentalize cellular processes. Further, changes in cellular cholesterol levels have been linked to alterations in the infection process of numerous viruses where the cholesterol dissipative agent, $\mathrm{M} \beta C D$, has been used to evaluate cholesterol-enriched lipid rafts in virus infection. $\mathrm{M} \beta C D$ is a strictly surface-acting agent that rapidly removes cholesterol from the plasma membrane. Some non-enveloped viruses, such as members of Picornaviridae and Reoviridae, are assembled in the cytoplasm and released by cell lysis. However, evidence has been advanced showing that exit from infected cells can occur in the 


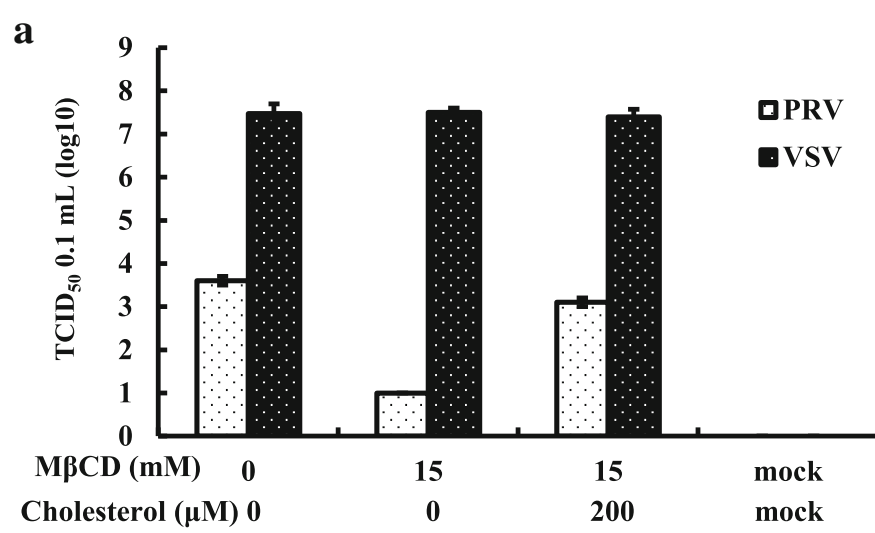

b PRV infection with 100 TCID $_{50}$ mock

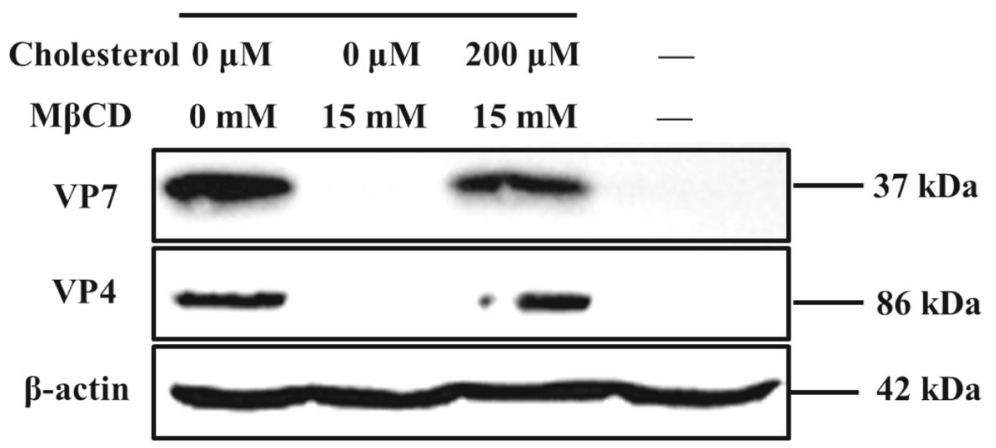

c VSV infection with 100 TCID $_{50}$ mock

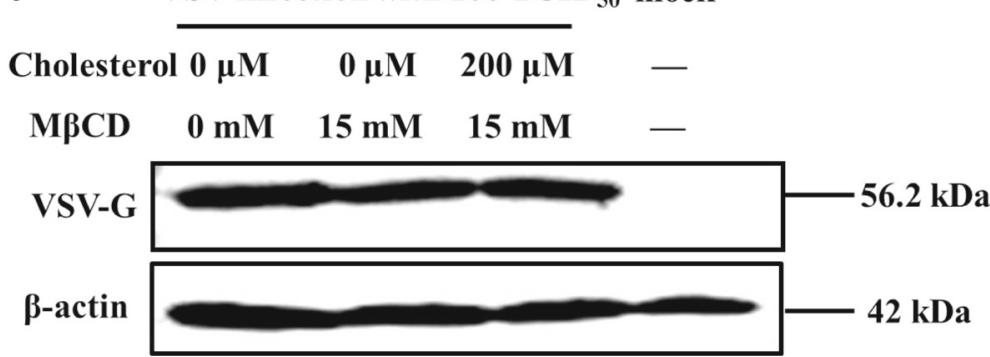

Fig. 6 Reversing the effects of MBCD on PRV entry using exogenous cholesterol. MA104 cells (PRV) and BHK-21 cells (VSV) were pretreated with 15 mM $\mathrm{MBCD}$ at $37^{\circ} \mathrm{C}$ for $30 \mathrm{~min}$, then replenished $200 \mu \mathrm{M}$ exogenous cholesterol at $37^{\circ} \mathrm{C}$ for $1 \mathrm{~h}$. Treated cells were then infected with PRV or VSV (100 TCID 50 ), respectively, and the homogenates examined by western blot analysis and virus titers. a Virus titer of PRV and VSV after treatment. b Western blot of PRV VP7 and VP4 proteins and $\beta$-actin. c Western blot of VSV G protein and $\beta$-actin. Western blots depict representative experiments. Error bars (Fig. 6a) indicate the standard deviations of three independent experiments

absence of cell lysis, suggesting that alternate paths may be utilized for egress by non-enveloped viruses [4]. Other members of the non-enveloped virus, such as RRV and bluetongue virus (BTV), along with a number of enveloped viruses such as transmissible gastroenteritis virus (TGEV) [27], porcine reproductive and respiratory syndrome virus (PRRSV) [32], porcine pseudorabies virus (PrV) [33], Rift valley fever virus [34] have been shown to be sensitive to $\mathrm{M} \beta C D$ treatment of host cells. Further, RRV and BTV have been shown to interact with lipids during the progress of infection suggesting the importance of cholesterolrich microdomains in the infection process. The entry of rotaviruses (RV) into host cells is a multistep process. Different rotavirus strains display different requirements for host cells. Some strains depend on the presence of sialic acid (SA) on the cell surface [35]. Others have demonstrated a requirement for several integrin during infection. As example, the VP4 protein of RV contains tripeptide sequence motifs for integrin $\alpha 2 \beta 1$ and $\alpha 4 \beta 1$, whereas VP7 contains ligand sites for integrin $\alpha x \beta 2$ and $\alpha 4 \beta 1$ [36, 37]. In addition, heat shock protein and certain gangliosides were identified as cellular molecules associated with RV entry.

The non-enveloped PRV, is a leading etiologic cause of severe dehydrating diarrhea in piglet worldwide. 


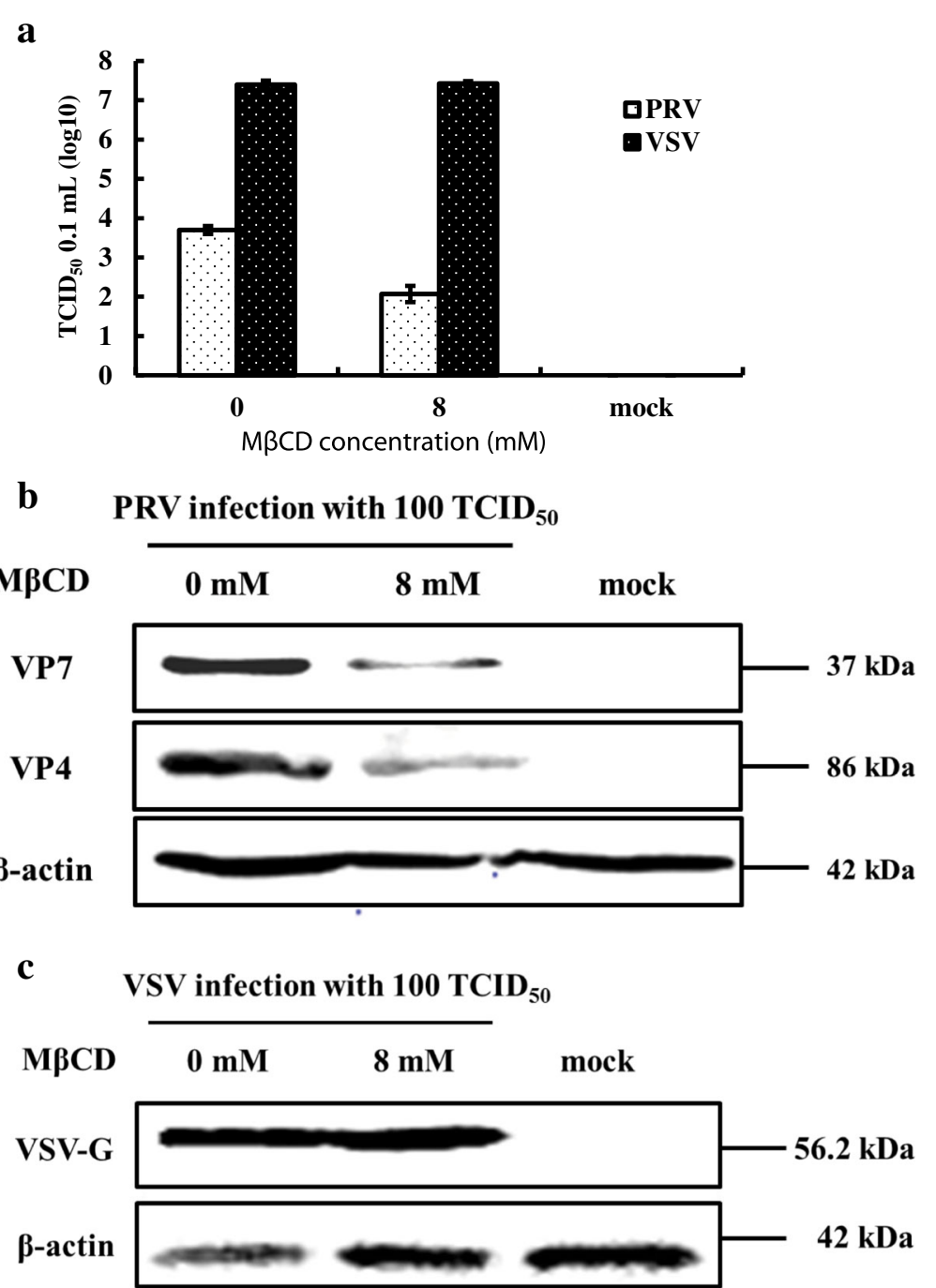

Fig. 7 Cholesterol and control of PRV post-entry. MA104 cells (PRV) and BHK-21 cells (VSV) were first infected at $37^{\circ} \mathrm{C}$ for $1 \mathrm{~h}$ then washed to remove extra virus. Cells were then treated with $8 \mathrm{mM} \mathrm{M} \beta C D$ incubated at $37^{\circ} \mathrm{C}$ for $24 \mathrm{~h}$. Antibodies to the PRV VP7 or VP4 proteins (PRV) and to the VSV G protein (VSV) were used to screen Western blots of cell homogenates. a Virus titer of PRV and VSV after treatment. b Western blot of PRV VP7 and VP4 proteins and $\beta$-actin. c Western blot of VSV G protein and $\beta$-actin. Western blots depict representative experiments. Error bars (Fig. 7a) indicate the standard deviations of three independent experiments

Consequently, there is an urgent need to develop effective preventive and therapeutic strategies to combat this pathogen. Currently, it is unknown whether or not cholesterolenriched lipid rafts which is present in the membranes of the host cells, is required for PRV infection, and if so, how it is associated with PRV infection. To address this question, cholesterol in the cellular membrane of MA104 cells was removed by $\mathrm{M} \beta C D$ treatment prior to PRV infection. Results demonstrated that lipid rafts depleted of cholesterol decreased the infectivity of PRV in a dose-dependent manner. Conversely, replenishment of cholesterol partially restored viral infection. These results are similar to those observed on RRV [14], BTV and poliovirus [6] which are also non-enveloped viruses $[5,38]$.
Our results collectively demonstrate that PRV infection interacts with cholesterol-enriched lipid rafts. First, direct treatment of the virus with $M \beta C D$ prior to infection had no effect in the infection process (data not shown) indicating the observed effects were unrelated to interactions between the drug and the virus. Second, the concentration of $M \beta C D$ and cholesterol used in this study did not generate significant adverse effects on cell viability as shown by MTT (data not shown). Third, the drug concentrations and the protocols are similar to those described in studies involving other viruses [27, 39]. Finally, co-localization studies showed that PRV VP7 protein and a recombinant GPI-anchor protein which has a predilection for lipid rafts, were localized to the lipid rafts in the plasma membranes of MA104 cells. 


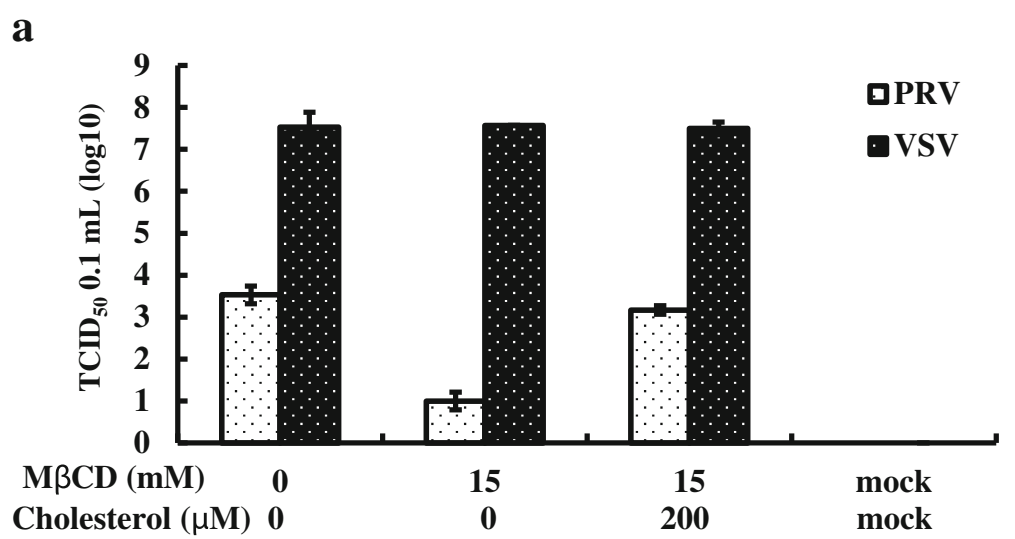

b PRV infection with 100 TCID $_{50}$ mock

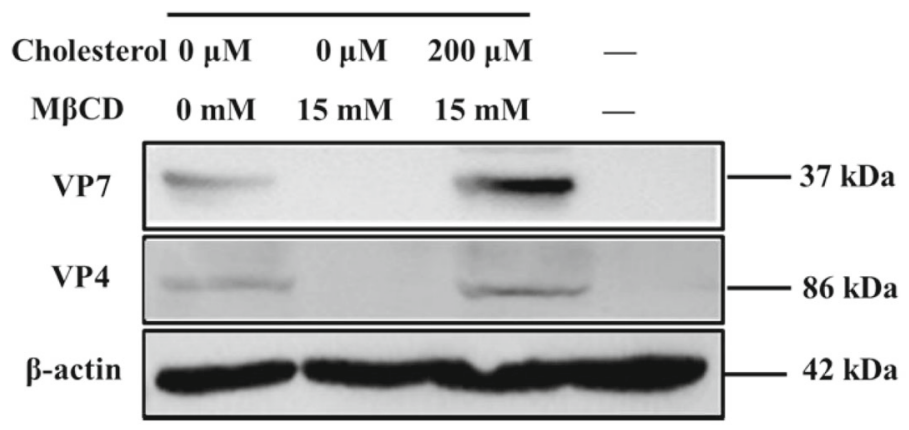

c

VSV infection with 100 TCID $_{50}$ mock

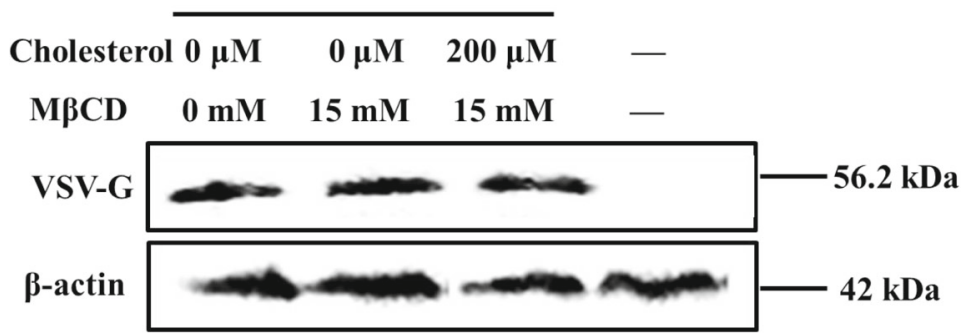

Fig. 8 Reversing the effects of MBCD on PRV post-entry using exogenous cholesterol. MA104 cells (PRV) and BHK-21 cells (VSV) that had been infected and treated with M $B C D$ were then incubated in the presence of $200 \mu \mathrm{M}$ exogenous cholesterol. Western blots and virus titers were performed to assess the effects of pre- and post-treatment on virus infection. a Virus titer of PRV and VSV after treatment. $\mathbf{b}$ Western blot of PRV VP7 and VP4 proteins and $\beta$-actin. c Western blot of VSV G protein and $\beta$-actin. Western blots depict representative experiments. Error bars (Fig. 8a) indicate the standard deviations of three independent experiments

Studies on the key stages of the PRV infection process requiring cholesterol have not been reported. In this study, we showed that adsorption of the virus onto the cell membrane at low temperatures was not affected by depletion of cholesterol; no significant differences were observed between M $\beta C D$-treated cells and mock cells. However, when cells were treated with $M \beta C D$ prior to or after virus entry, PRV infection declined in a dosedependent manner. The replenishing of exogenous cholesterol reversed these affects indicating that cholesterol depletion affected mechanisms involved in the entry of the virus and one or more mechanism downstream of virus entry. Similar results were also observed with the bovine rotavirus (BRV) where cholesterol depletion significantly impaired BRV entry and assembly but did not reduce BRV replication [39]. These results suggested that PRV entry may be inhibited by cholesterol depletion though disturbing lipid-raft-dependent endocytosis.

In summary, lipid rafts play vital roles in PRV infection, and plasma membrane-based cholesterol is a key determinant for entry and post-entry stages of PRV infection. By depleting plasma membrane cholesterol we were able 
to provide a direct link between cholesterol levels, lipid rafts and the ability of PRV to infect host cells. Future studies are needed to investigate synergistic effects between $\mathrm{M} \beta C D$ and other drugs capable of disrupting lipid rafts in porcine intestinal epithelial cell cultures.

\section{Conclusions}

Our results reveal the mechanism of PRV infection that membrane-cholesterol localized to lipid rafts is an indispensable biomolecule for PRV infection during the entry and post-entry into the cells rather than virus binding on cell surface; on the other hand, $\mathrm{M} \beta C D$, a cellular cholesterol-depletion agent, inhibit the PRV infection on the susceptible cells, have a huge potential to develop a new anti-viral strategy.

\section{Abbreviations}

BRV: Bovine rotavirus; BTV: Bluetongue virus; CPE: Cytopathic effects; DMEM: Dulbecco's Modified Eagle Medium; FCS: Fetal calf serum; GPI: Glycosyl-phosphatidylinositol; h: Hours; HIV: Human immunodeficiency virus; HRP: Horseradish peroxidase; IFA: Indirect immunofluorescence assay; min: Minute; MTT: Mosmann based assay; M $\beta C D$ : Methyl- $\beta$-cyclodextrin; PBS: Phosphate-buffered saline; PRRSV: Porcine reproductive and respiratory syndrome virus; PrV: Porcine pseudorabies virus; PRV: Porcine rotavirus; RRV: Rhesus rotavirus; SA: Sialic acid; SV40: Simian virus 40; TBST: Tris-buffered saline containing $0.05 \%$ Tween $20 ; \mathrm{TCID}_{50}$ : The $50 \%$ tissue culture infectious dose; TGEV: Transmissible gastroenteritis virus; VSV: Vesicular stomatitis virus

\section{Acknowledgements}

Not Applicable.

\section{Funding}

This work was supported by the China Postdoctoral Science Foundation for the 62nd batch (2017M621), Postdoctoral Foundation in Heilongjiang Province (LBH-Z17013, LBH-Z17035), National Natural Science Foundation of China (31201911, 31300758 and 31501914), National Science \& Technology Pillar Program during the Twelfth Five-year Plan Period (2013BAD12B04), and Research Fund for the Doctoral Program of Higher Education of China (Ph.D. Student Supervisor Type) of Ministry of Education of P.R. China, No. 20122325110019

\section{Availability of data and materials}

The datasets used and/or analysed during the current study available from the corresponding author on reasonable request.

\section{Authors' contributions}

$X J D$ and $Y L$ contributed equally to this work, and they are both co-first authors. $X J D, Y L$ participated in the design of this study, carried out all the studies, performed the statistical analysis and drafted the manuscript, XLL carried out partial infection experiments. YL, JLH and WJZ did much revision work during the major or minor revision, DSZ, XFR, ND and GXL supervised the work and edited the final version of this manuscript. All authors have read and approved the final version of the manuscript.

\section{Ethics approval and consent to participate}

Not applicable.

\section{Consent for publication}

Not applicable.

\section{Competing interests}

The authors declare that they have no competing interests.

\section{Publisher's Note}

Springer Nature remains neutral with regard to jurisdictional claims in published maps and institutional affiliations.

\section{Author details}

'Northeast Agricultural University, No. 59 Mucai Street, Xiangfang District, Harbin 150030, China. ${ }^{2}$ Animal Parasitic Diseases Laboratory, Agricultural Research Service, United States Department of Agriculture, Building 1180, BARC-East, Beltsville, MD 20705, USA.

Received: 21 March 2016 Accepted: 28 January 2018

Published online: 12 February 2018

\section{References}

1. Parashar UD, Hummelman EG, Bresee JS, Miller MA, Glass RI. Global illness and deaths caused by rotavirus disease in children. Emerg Infect Dis. 2003;9: 565-72.

2. Desselberger U. Rotaviruses. Virus Res. 2014;190C:75-96.

3. Graham KL, Halasz P, Tan Y, Hewish MJ, Takada Y, Mackow ER, Robinson MK, Coulson BS. Integrin-using rotaviruses bind alpha2beta1 integrin alpha2 I domain via VP4 DGE sequence and recognize alphaXbeta2 and alphaVbeta3 by using VP7 during cell entry. J Virol. 2003;77:9969-78.

4. Bhattacharya B, Roy P. Role of lipids on entry and exit of bluetongue virus, a complex non-enveloped virus. Viruses. 2010:2:1218-35.

5. Clayson ET, Brando LV, Compans RW. Release of simian virus 40 virions from epithelial cells is polarized and occurs without cell lysis. J Virol. 1989:63:2278-88.

6. Danthi P, Chow M. Cholesterol removal by methyl-beta-cyclodextrin inhibits poliovirus entry. J Virol. 2004;78:33-41.

7. Cuadras MA, Greenberg HB. Rotavirus infectious particles use lipid rafts during replication for transport to the cell surface in vitro and in vivo. Virology. 2003;313:308-21.

8. Mohan KV, Muller J, Atreya CD. Defective rotavirus particle assembly in lovastatin-treated MA104 cells. Arch Virol. 2008;153:2283-90.

9. Fritz JV, Tibroni N, Keppler OT, Fackler OT. HIV-1 Vpu's lipid raft association is dispensable for counteraction of the particle release restriction imposed by CD317/Tetherin. Virology. 2012;424:33-44.

10. Robinzon S, Dafa-Berger A, Dyer MD, Paeper B, Proll SC, Teal TH, Rom S, Fishman D, Rager-Zisman B, Katze MG. Impaired cholesterol biosynthesis in a neuronal cell line persistently infected with measles virus. J Virol. 2009;83: 5495-504.

11. Godefroy C, Dahmane S, Dosset P, Adam O, Nicolai MC, Ronzon F, Milhiet PE. Mimicking influenza virus fusion using supported lipid Bilayers. Langmuir. 2014;30(38):11394-400.

12. Morita M, Kuba K, Ichikawa A, Nakayama M, Katahira J, Iwamoto R, Watanebe T, Sakabe S, Daidoji T, Nakamura S, et al. The lipid mediator protectin D1 inhibits influenza virus replication and improves severe influenza. Cell. 2013;153:112-25.

13. Veit M, Engel S, Thaa B, Scolari S, Herrmann A. Lipid domain association of influenza virus proteins detected by dynamic fluorescence microscopy techniques. Cell Microbiol. 2013;15:179-89.

14. Isa P, Realpe M, Romero P, Lopez S, Arias CF. Rotavirus RRV associates with lipid membrane microdomains during cell entry. Virology. 2004;322:370-81.

15. Dansako H, Hiramoto H, Ikeda M, Wakita T, Kato N. Rab18 is required for viral assembly of hepatitis $C$ virus through trafficking of the core protein to lipid droplets. Virology. 2014;462-463:166-74.

16. Wei Q, Zhang F, Richardson MM, Roy NH, Rodgers W, Liu Y, Fu C, Ding Y, Zhao W, Huang C, et al. CD82 restrains angiogenesis by altering lipid raft clustering and CD44 trafficking in endothelial cells. Circulation. 2014;130(17): 1493-504.

17. Cuddy LK, Winick-Ng W, Rylett RJ. Regulation of the high-affinity choline transporter activity and trafficking by its association with cholesterol-rich lipid rafts. J Neurochem. 2014;128:725-40.

18. Jordy AB, Serup AK, Karstoft K, Pilegaard H, Kiens B, Jeppesen J. Insulin sensitivity is independent of lipid binding protein trafficking at the plasma membrane in human skeletal muscle: effect of a 3-day, high-fat diet. Am J Physiol Regul Integr Comp Physiol. 2014;307(9):R1136-45.

19. Bavari S, Bosio CM, Wiegand E, Ruthel G, Will AB, Geisbert TW, Hevey M, Schmaljohn C, Schmaljohn A, Aman MJ. Lipid raft microdomains: a gateway for compartmentalized trafficking of Ebola and Marburg viruses. J Exp Med. 2002:195:593-602

20. Norkin LC, Kuksin D. The caveolae-mediated sv40 entry pathway bypasses the golgi complex en route to the endoplasmic reticulum. Virol J. 2005:2:38

21. Van Wilgenburg B, Moore MD, James WS, Cowley SA. The productive entry pathway of HIV-1 in macrophages is dependent on endocytosis through lipid rafts containing CD4. PLoS One. 2014;9:e86071. 
22. Mikulak J, Singhal PC. HIV-1 entry into human podocytes is mediated through lipid rafts. Kidney Int. 2010;77:72-3. 73-74

23. Carter GC, Bernstone L, Sangani D, Bee JW, Harder T, James W. HIV entry in macrophages is dependent on intact lipid rafts. Virology. 2009;386:192-202.

24. Campbell SM, Crowe SM, Mak J. Lipid rafts and HIV-1: from viral entry to assembly of progeny virions. J Clin Virol. 2001;22:217-27.

25. Pietiainen V, Marjomaki V, Upla P, Pelkmans L, Helenius A, Hyypia T. Echovirus 1 endocytosis into caveosomes requires lipid rafts, dynamin II, and signaling events. Mol Biol Cell. 2004;15:4911-25.

26. Zhu J, Yang Q, Cao L, Dou X, Zhao J, Zhu W, Ding F, Bu RE, Suo S, Ren Y, et al. Development of porcine rotavirus vp6 protein based ELISA for differentiation of this virus and other viruses. Virol J. 2013;10:91.

27. Ren X, Glende J, Yin J, Schwegmann-Wessels C, Herrler G. Importance of cholesterol for infection of cells by transmissible gastroenteritis virus. Virus Res. 2008;137:220-4

28. Ren X, Dou X, Hao Y, Sun L, Wei X. Expression VP4 complete protein and polyclonal antibodies preparation or detection of porcine rotavirus DN30209 strain. J Northeast Agric Univ. 2014;45:10-7.

29. Denizot F, Lang R. Rapid colorimetric assay for cell growth and survival. Modifications to the tetrazolium dye procedure giving improved sensitivity and reliability. J Immunol Methods. 1986;89:271-7.

30. Lingwood D, Simons K. Lipid rafts as a membrane-organizing principle. Science. 2010;327:46-50.

31. Nayak DP, Hui EK. The role of lipid microdomains in virus biology. Subcell Biochem. 2004;37:443-91.

32. Huang L, Zhang YP, Yu YL, Sun MX, Li C, Chen PY, Mao X. Role of lipid rafts in porcine reproductive and respiratory syndrome virus infection in MARC145 cells. Biochem Biophys Res Commun. 2011;414:545-50.

33. Ren X, Yin J, Li G, Herrler G. Cholesterol dependence of pseudorabies herpesvirus entry. Curr Microbiol. 2011;62:261-6.

34. Harmon B, Schudel BR, Maar D, Kozina C, lkegami T, Tseng CT, Negrete OA. Rift Valley fever virus strain MP-12 enters mammalian host cells via caveola-mediated endocytosis. J Virol. 2012;86:12954-70.

35. Arias CF, Isa P, Guerrero CA, Mendez E, Zarate S, Lopez T, Espinosa R, Romero P, Lopez S. Molecular biology of rotavirus cell entry. Arch Med Res. 2002;33:356-61.

36. Guerrero CA, Moreno LP. Rotavirus receptor proteins $\mathrm{Hsc70}$ and integrin alphavbeta3 are located in the lipid microdomains of animal intestinal cells. Acta Virol. 2012;56:63-70.

37. Hewish MJ, Takada Y, Coulson BS. Integrins alpha2beta1 and alpha4beta1 can mediate SA11 rotavirus attachment and entry into cells. J Virol. 2000;74:228-36.

38 Danthi P, Chow M. Cholesterol removal by Methyl-beta-Cyclodextrin inhibits poliovirus entry. J Virol. 2004;78(1):33-41.

39. Cui J, Fu X, Xie J, Gao M, Hong M, Chen Y, Su S, Li S. Critical role of cellular cholesterol in bovine rotavirus infection. Virol J. 2014:11:98.

\section{Submit your next manuscript to BioMed Central and we will help you at every step:}

- We accept pre-submission inquiries

- Our selector tool helps you to find the most relevant journal

- We provide round the clock customer support

- Convenient online submission

- Thorough peer review

- Inclusion in PubMed and all major indexing services

- Maximum visibility for your research

Submit your manuscript at www.biomedcentral.com/submit
Biomed Central 